\title{
TRAVEL SELFIE DAN DESTINATION IMAGE: STUDI KASUS TAMAN BUNGA JALAN JALUR LINGKAR SELATAN (JJLS) YOGYAKARTA
}

\author{
Ari Yuniarso $^{1}$, Tri Wiyana ${ }^{2}$, Arif Zulkarnain ${ }^{3}$, dan Iwan Khrisnanto ${ }^{4}$ \\ Hotel Management Department, Faculty of Economics and Communication, Bina Nusantara University \\ ${ }^{1}$ ari_y@binus.edu, ${ }^{2}$ triwiyana@binus.edu, ${ }^{3}$ arief.zulkarnain@binus.edu, ${ }^{4}$ iwan.khrisnanto@binus.ac.id
}

\begin{abstract}
ABSTRAK:
Fotografi dan pariwisata saat ini dianggap tidak dapat dipisahkan. Secara umum, tren yang terjadi dalam fotografi serta teknologinya telah berubah secara signifikan dan telah menjadi jauh lebih kompleks dan berbasis online media. Media sosial dan beberapa jejaring sosial telah muncul sebagai suatu fenomena yang sebagai sumber informasi online baru yang dibuat, diinisiasi, diedarkan dan digunakan oleh konsumen yang bermaksud untuk mendidik satu sama lain tentang produk, merek, layanan, kepribadian, dan masal. Pembahasan dalam penelitian ini adalah tentang travel selfie sebagai media alternatif promosi destinasi wisata. Obyek penelitian ini berdasarkan fenomena kebun bunga di sepanjang pinggir Jalan Jalur Lintas Selatan(JJLS) Desa Srigading, Kecamatan Sanden, Kabupaten Bantul, Yogyakarta. Penelitian ini menggunakan pendekatan kualitatif dengan metode studi kasus. Data yang akan dianalisis adalah hasil interview pengunjung dan pemilik kebun bunga. Juga dilakukan pengamatan foto-foto yang muncul di media sosial untuk melihat respon terhadap obyek wisata tersebut. Tujuan penelitian ini untuk mengetahui kategori paling populer terhadap suatu citra destinasi, dan selanjutnya analisa deskripsi dilakukan untuk mendapatkan model bahwa travel selfiedianggap sebagai elemen yang lebih penting untuk media alternatif destinasi wisata.
\end{abstract}

Kata Kunci: travel selfie, social media, destination image

\begin{abstract}
:
Photography and tourism are now considered inseparable. In general, trends in photography and technology have changed significantly and have become much more complex and online-based media. Social media and social networks have emerged as a phenomenon as a new source of online information created, initiated, circulated and used by consumers who intend to educate each other about products, brands, services, personalities, and the masses. The discussion in this study is about travel selfie as an alternative media promotion of tourist destinations. The object of this research is based on flower garden phenomenon along the edge of Jalan Jalur Lintas Selatan (JJLS) of Desa Srigading, Kecamatan Sanden, Kabupaten Bantul, Yogyakarta. This research uses qualitative approach with case study method. The data to be analyzed is the result of interviews of visitors and flower garden owners. Also observed photographs appearing on social media to see the response to these attractions. The purpose of this research is to know the most popular category of destination image, and further description
\end{abstract}




\section{National Conference of Creative Industry: \\ Sustainable Tourism Industry for Economic Development}

Universitas Bunda Mulia, Jakarta, 5-6 September 2018

e-ISSN No: 2622-7436

analysis is done to get the model that travel selfie considered as more important element for alternative media of tourist destination.

Keywords: travel selfie, social media, destination image

\section{PENDAHULUAN}

Teknologi semakin berkembang pesat dengan banyaknya hal-hal baru yang turut menyertai kehidupan manusia di saat ini. Untuk saat ini, salah satu hal yang sedang booming dan terlihat wajib dimiliki oleh setiap orang adalah smartphone. Perbedaan antara smartphone saat ini dan smartphone awal adalah bahwa smartphone awal sebagian besar ditujukan untuk pengguna korporat dan digunakan sebagai perangkat perusahaan dan juga ponsel itu terlalu mahal untuk konsumen umum (Brad, 2010). Indonesia mampu menjadi basis produksi bagi pengembangan industri perangkat telekomunikasi kelas dunia. Terlebih lagi dengan didukung potensi pasar dalam negeri yang sangat besar serta sejumlah produsen komponen lokal yang cukup kompetitif. Penggunaan smartphone meliputi kehidupan modern dan ada manfaat yang tak perlu diragukan. Sebuah smartphone memungkinkan pengguna untuk menjaga kontak rutin dengan keluarga dan teman melalui media sosial. Dalam beberapa tahun terakhir, smartphone telah digunakan secara global (Pew Research Center, 13 Februari 2014).

Data yang diperoleh Kementerian Perindustrian, saat ini terdapat 24 perusahaan manufaktur komponen produk ponsel dan tablet di dalam negeri. Sementara itu, berdasarkan laporan e-Marketer, pengguna aktif smartphone di Indonesia akan tumbuh dari 55 juta orang pada tahun 2015 menjadi 100 juta orang tahun 2018. Dengan jumlah tersebut, Indonesia akan menjadi negara dengan pengguna aktif smartphone terbesar keempat di dunia setelah China, India, dan Amerika (Andita , 2018). Sementara pengguna telepon seluler (ponsel) di tanah air mencapai 371,4 juta pengguna atau 142 persen dari total populasi sebanyak 262 juta jiwa. Artinya, rata-rata setiap penduduk memakai 1,4 telepon seluler karena satu orang terkadang menggunakan 2-3 kartu telepon seluler. Sementara kaum urban Indonesia mencapai 55 persen dari total populasi (Katadata, 2017).

Kamera kini dianggap sebagai salah satu fitur utama smartphone yang masuk ke dalam prioritas penggunanya, "selfie can be defined as a self-portrait taken by oneself using a digital camera or smartphone”(Qiu, Lu, Yang, Qu, \& Zhu, 2015). Aktivitas selfie adalah tren baru gaya hidup modern yang dapat dilihat dari bagaimana informan atau pelaku selfie konsumtif penggunaan kuota paket data internet, pembelian peralatan pendukung untuk selfie, atau pelaku selfie bertujuan menjadi populer di media sosial (Harisa, 2017). Setiap hari, ribuan foto diunggah secara online di jaringan media sosial. Foto-foto yang posting ini berbagai maksud dan tujuan, salah satunya adalahposting tentang promosi destinasi.

Fenomena menarik keramaian yang tidak biasa terjadi di Jalan Jalur Lintas Selatan (JJLS) di sisi utara Pantai Samas, Dusun Tegalsari, Srigading, Kecamatan Sanden, Kabupaten Bantul, Daerah Istimewa Yogyakarta. Belakangan berwisata sembari berswafoto banyak digemari. Tidak sedikit pula kini spot-spot foto dengan latar yang menarik tersedia. karena terlihat indah banyak pengunjung yang datang untuk berswafoto. Foto-foto tentang kecantikan bunga ini pun beredar di media sosial beberapa hari terakhir. Dalam proses ini, wisatawan memainkan peran utama dalam 


\section{National Conference of Creative Industry: \\ Sustainable Tourism Industry for Economic Development}

Universitas Bunda Mulia, Jakarta, 5-6 September 2018 e-ISSN No: 2622-7436

pembentukan dan transmisi destination image kepada orang lain melalui word-of-mouth (WOM) (Comprubi, Guia, \& Comas, 2009). Sarana multimedia juga berperan terhadap pembentukan proses ini, "the tools of co-creation are manifested through articles, comments, tweets, blogs or vlogs, wikis, discussions in forums or chats, podcasts, or any kind of uploaded images, videos or audio files"(Munar, 2012). Penelitian ini menyajikan analisis perilaku travel selfie terhadap pembentukan destination image, dengan obyek taman bunga di area Jalan Lingkar Selatan Yogyakarta. Tujuan dari penelitian ini untuk mengetahui pola pembentukan destination image dengan sarana media sosial khususnya periku travel selfie. Dengan pendekatan metode kualitatif yang menganalisis perilaku wisatawan dan pengamatan postingan media sosial dalam penyebutan nama branding sebuah destinasi.

\section{TINJAUAN PUSTAKA}

\section{Travel Selfie}

The Oxford Dictionary mendifinisikan selfie sebagai "a photograph that one has taken of oneself, typically one taken with a smartphone or webcam and shared via social media," and it elaborates with the following example: "Occasional selfies are acceptable, but posting a new picture of yourself everyday isn't necessary". Traveling saat ini telah menjadi gaya hidup tersendiri dan bukan sekadar kegiatan yang bisa dilakukan kelompok tertentu saja. Saat traveling ke sebuah tempat, apalagi dengan pemandangan yang indah, pasti tergoda untuk mengambil foto selfie. Penggunaan teknologi smartphone melingkupi kehidupan modern dan ada banyak sekali manfaat ponsel cerdas dalam meningkatkan the international traveller's experience(Patel \& Jermacane, 2015). Penelitian inimenyatakan "management implications to help tourism practitioners successfully distribute desired destination images using their clienteles' strategic self-presentation behaviors"'(Lyu, 2016).Melalui proses ini, wisatawan dapat menganggap karakteristik yang mereka kaitkan dengan pemandangan wisata ke diri mereka sendiri (Dinhopl \& Gretzel, 2016). Banyak wisatawan yang terlibat lebih jauh dalam local landscape; memilih ke tingkat yang lebih besar atau lebih kecil untuk mengakulturasi dan menjadi terlibat erat dengan host culturesebagai contoh (Rasmi, Ng, Lee, \& Soutar, 2014).

Perspektif yang mendasari kategori pertama studi menekankanbahwa selfie adalah alat yang efektif untuk presentasi diri. Dalam hal ini, selfie tidak hanya dapat mencerminkan kepribadian individu tetapi juga membantu menyampaikan konsep diri ideal mereka, mengingat bahwa selfie mudah dimanipulasi, "not many studies have empirically investigated how takingand sharing selfies in fluence selfie takers")(Chua \& Chang, 2016). Selfie telah menjadi sangat populer dan hampir tidak mungkin untuk mengunjungi situs media sosial mana pun tanpa melihat wajah teman-teman kami dalam jarak dekat. Selfie adalah potret diri seseorang (atau diri sendiri dan orang lain), yang diambil dengan kamera (ponsel) yang dipegang dengan lengan atau diarahkan ke cermin, yang biasanya dibagikan melalui media sosial (Sorokowski, et al., 2015), atau “the selfie as a prototype of expressive inauthenticity”(Lobinger \& Brantner, 2015), sebagai cara menunjukkan yang tidak autentik, sering meniru model peran dari budaya bintang model dan selebriti daripada menunjukkan diri sejati seseorang.Unsur selfies lain yang berhubungan dengan penilaian tidak autentisitas adalah visibilitas proses produksi fotografi. 


\section{National Conference of Creative Industry: \\ Sustainable Tourism Industry for Economic Development}

Universitas Bunda Mulia, Jakarta, 5-6 September 2018

e-ISSN No: 2622-7436

\section{Media Sosial}

Media sosial telah menjadi alat yang semakin populer untuk terlibat dalam perilaku sosial (Hart, 2011; Spiliotopoulos \& Oakley, 2013; Ryan, Allen, Gray, \& McInerney, 2017). Ada berbagai bentuk media sosial yang tersedia, termasuk situs jejaring sosial (misalnya, Facebook, Instagram, Snapchat), layanan olahpesan instan (misalnya, WhatsApp, Facebook Messenger), situs makro dan mikro-blogging, (misalnya, Twitter, wordPress, Tumblr), game online besar-besaran multigame (misalnya, World of Warcraft, League of Legends), dan dunia virtual (mis., Second Life). Situs jejaring sosial (SNS) bisa dibilang merupakan bentuk media sosial paling populer yang digunakan saat ini. Sebagai contoh statistik dari Facebook menunjukkan bahwa situs ini memiliki lebih dari satumiliar pengguna harian di seluruh dunia (Facebook, 2016). Karakkter dasar dari media sosial adalah terbentuknya jaringan antar pengguna. Jaringan ini tidak sekedar memperluas hubungan pertemanan atau pengikut (follower) di internet semata, tetapi juga harus dibangun dengan interaksi antar pengguna tersebut (Nasrullah, 2015).

Media sosial merupakan salah satu aktivitas online favorit yang digunakan oleh publik hampir setiap hari. Artikel yang ditulis oleh Davidson pada tahun 2015 lalu, pengguna internet menghabiskan sekitar satu jam 40 menit perhari di situs sosial, jika dibandingkan dengan satu:empat waktu yang digunakan untuk membaca $e$-mail yang merupakan aktivitas umum jika berkaitan dengan internet (Davidson, 2015). Para praktisi pemasaran yang disurvei dalam penelitian Stelzner tersebut mayoritas menyatakan ingin lebih mempelajari taktik sosial yang paling efektif dan cara terbaik untuk melibatkan audiens mereka dengan media sosial (Stelzner, 2016). Meskipun ada beberapa penelitian kuantitatif yang dilakukan menganalisis posting selfie di media sosial, sebagian besar penelitian sebelumnya telah berfokus pada menemukan korelasi antara tipe kepribadian dan penggunaan media sosial (Omarzu, 2000; Treem \& Leonardi, 2012; Williamson, Stohlman , \& Polinsky , 2017). Ketika seseorang terpapar dengan media digital dan internet dalam kurun waktu yang lama, hal tersebut akan mengembangkan cara baru untuk bersosialisasi, berinteraksi, berpikir dan berperilaku (Selviana, 2106; Harisa, 2017).

\section{Destination Image}

Image didefinisikan sebagai representasi mental, serangkaian keyakinan, ide, dan kesan yang dimiliki orang-orang dari suatu destinasi (Crompton, 1979; Molinillo, Cabanillas, \& Sanchez, 2017). Destination image secara drastis sudah banyak dievaluasi. Penelitian pertama pada destination image dalam industri pariwisata pada awal tahun 1970-an. Sejak saat itu destination image telah menjadi sangat penting dikalangan peneliti (Frochot \& Batat, 2013). Permasalahan dimensi destination imagetelah membagi literatur yang masih ada, dan menurut (Gartner, 1994; Molinillo, Cabanillas, \& Sanchez, 2017) proses pembentukan citra melibatkan tiga komponen: kognitif, afektif, dan konatif. Studi lain menganalisis selfie image yang dikumpulkan dengan aplikasi Self-Pano: jarak, lokasi, dan gaya selfie dieksplorasi, dari hasil tersebut dapat digunakan sebagai referensi untuk pengembangan future selfie stick development(Lee \& Kosasih, 2017). Penelitian menunjukkan bahwa image yang baik merupakan kunci utama yang dipegang secara luas dari suatu negara dan destination image cenderung mempengaruhi loyalitas wisatawan terhadap suatu destinasi, namun stereotyping negara memainkan peran yang lebih penting daripada destination 
imagedalam memprediksi niat perilaku untuk mengunjungi international destination (Chung \& Chen, 2018).

\section{METODE PENELITIAN}

Metode penelitian dengan pendekatan kualitatif, desain metode yang digunakan adalah dari sifat kualitatif, mencari pemahaman kegiatan manusia dan pemahaman tentang realitas fenomena (Glaser \& Strauss, 1967)grounded theory, tahap pertama adalah tinjauan literatur mendalam yang digunakan untuk mengeksplorasi latar belakang studi yang sudah dikenal serta untuk mendukung travel selfie, destination image dan topik-topik media sosial yang relevan dalam penelitian ini.

Tahap kedua selanjutnya melakukan interview dengan para wisatawan sebanyak 10 wisatawan di obyek wisata kebun bunga kawasan Jalan Jalur Lintas Selatan (JJLS), Bantul, Yogyakarta. Tujuannya adalah untuk mendapatkan indikasi awal terhadap destination image. Pertanyaan yang sebagai instrument adalah sebagai berikut:

Tabel 1. Daftar Pertanyaan Pengunjung

\begin{tabular}{clccc}
\hline No & \multicolumn{1}{c}{ Pertanyaan } & & Jawaban Pilihan & \\
\hline 1. & $\begin{array}{l}\text { Dari mana anda } \\
\text { mengetahui } \begin{array}{c}\text { Internet } \\
\text { obyek } \\
\text { wisata Kebun Bunga? }\end{array}\end{array}$ & Media Sosial & Teman & Kadang \\
\hline 2. & $\begin{array}{l}\text { Apakah setiap anda } \\
\text { travelling selalu selfie }\end{array}$ & Ya & Tidak & Twitter \\
\hline 3. & $\begin{array}{l}\text { Dimana posting selfie } \\
\text { anda? }\end{array}$ & Instagram & Facebook & Destinasi JJLS \\
\hline 4. & $\begin{array}{l}\text { Apa } \\
\text { istilah/brand/hastag/taga } \\
\text { r wisata kebun bunga? }\end{array}$ & Kebun Bunga & Taman Bunga & Mungkin \\
\hline 5. & $\begin{array}{l}\text { Anda akan mengunjungi } \\
\text { kembali? }\end{array}$ & Ya & Tidak & \\
\hline
\end{tabular}

Sumber: Peneliti (2018)

Tahap kedua, content analysis sebagai metode penelitian obyektif, sistematis dan kuantitatif diterapkan untuk menjawab pertanyaan penelitian yang disebutkan sebelumnya. Seperti Kim dan Stepchenkova (Kim \& Stepchenkova, 2015) mengidentifikasi, ada dua jenis konten yang dapat dianalisis: manifes dan konten laten. Seperti dalam hal ini struktur permukaan fotografi telah diteliti, itu adalah tipe konten yang nyata yang dipelajari.

Content analysis dapat dipergunakan jika memiliki syarat berikut: (1) Data yang tersedia sebagian besar terdiri dari bahan-bahan yang terdokumentasi (buku, surat kabar, pita rekaman, naskah/manuscript); (2) Ada keterangan pelengkap atau kerangka teori tertentu yang menerangkan tentang dan sebagai metode pendekatan terhadap data tersebut; (3) Peneliti memiliki kemampuan teknis untuk mengolah bahan-bahan/data- 
data yang dikumpulkannya karena sebagian dokumentasi tersebut bersifat sangat khas/spesifik.

Dengan melakukan review dan pesan yang disampaikan melalui sosial media sebanyak 100 postingan komentar fenomena sosialseperti prasangka, pesan, diskriminasi atau mengubah simbol budaya dalam konten komunikasi mengenai obyek penelitian ini selama periode Juni sampai dengan Juli 2018. Dan pada akhirnya dibuat kesimpulan kategori paling populer terhadap suatu citra destinasi, dan selanjutnya analisa deskripsi dilakukan untuk mendapatkan model bahwa travel selfiedianggap sebagai elemen yang lebih penting untuk media alternatif destinasi wisata.

\section{HASIL PENELITIAN DAN PEMBAHASAN}

Kriteria responden yang menjadi sumber penelitian ini adalah wisatawan lokal yang berkunjung di kebun bunga kawasan Jalan Jalur Lintas Selatan (JJLS), Bantul, Yogyakarta. Total responden sebanyak 10 wisatawan untuk menentukan indikasi awal dalam proses content analysi.

Tabel 2. Persentase Jawaban Responden

\begin{tabular}{|c|c|c|c|c|}
\hline \multirow{2}{*}{$\begin{array}{l}\text { No } \\
1 .\end{array}$} & Pertanyaan & \multicolumn{3}{|c|}{ Jawaban Pilihan } \\
\hline & $\begin{array}{l}\text { Dari mana anda } \\
\text { mengetahui obyek wisata } \\
\text { Kebun Bunga? }\end{array}$ & $\begin{array}{l}\text { Media Sosial } \\
\quad(90 \%)\end{array}$ & Teman $(1 \%)$ & Internet $(0 \%)$ \\
\hline 2. & $\begin{array}{l}\text { Apakah setiap anda } \\
\text { travelling selalu selfie }\end{array}$ & Ya (100\%) & Tidak $(0 \%)$ & Kadang (0\%) \\
\hline 3. & $\begin{array}{l}\text { Dimana posting selfie } \\
\text { anda? }\end{array}$ & $\begin{array}{c}\text { Instagram(20 } \\
\%)\end{array}$ & $\begin{array}{l}\text { Facebook } \\
(80 \%)\end{array}$ & Twitter $(0 \%)$ \\
\hline 4. & $\begin{array}{l}\text { Apa } \\
\text { istilah/brand/hastag/tagar } \\
\text { wisata kebun bunga? }\end{array}$ & $\begin{array}{l}\text { Kebun Bunga } \\
\quad(50 \%)\end{array}$ & $\begin{array}{l}\text { Taman Bunga } \\
\quad(50 \%)\end{array}$ & $\begin{array}{c}\text { Destinasi JJLS } \\
(0 \%)\end{array}$ \\
\hline 5. & $\begin{array}{l}\text { Anda akan mengunjungi } \\
\text { kembali? }\end{array}$ & Ya $(70 \%)$ & Tidak (10\%) & $\begin{array}{l}\text { Mungkin } \\
(20 \%)\end{array}$ \\
\hline
\end{tabular}

Sumber: Pengolahan Data (2018)

Berikutnya mengunduh secara manual foto-foto dari jaringan facebook dan instagramyang disebutkan di atas dan mengikuti folksonomies yang telah ditentukan sebelumnya, selfies wisata telah dikategorikan, menurut isinya, ke dalam kelompok yang terinspirasi oleh penelitian yang dilakukan oleh (Rabassa, Paniagua, \& Setó, 2014) dan memodifikasi dan disesuaikan untuk penelitian ini. Semua kategori dan subkategori dapat dilihat pada tabel berikut:

Tabel 3. Kategori dan Sub Kategori

\begin{tabular}{llcc}
\hline \multicolumn{1}{c}{ Kategori } & \multicolumn{2}{c}{ Sub Kategori } \\
\hline Image & Kebun Bunga & Taman Bunga & Kebun Bunga Bantul \\
\hline Alam & Ecotourism & - & - \\
\hline
\end{tabular}


National Conference of Creative Industry: Sustainable Tourism Industry for Economic Development

Universitas Bunda Mulia, Jakarta, 5-6 September 2018 e-ISSN No: 2622-7436

\begin{tabular}{lcrc}
\hline Lokasi & Bantul & Jogja & Jalur Lintas Selatan \\
\hline Pengunjung & - & - & - \\
\hline \multicolumn{2}{c}{ Sumber: } \\
\hline
\end{tabular}

Sumber: Peneliti (2018)

Menggunakan metode penelitiancontent analysis, dari semua unggahan foto selfiedianalisis, sampel dari 100 postinganselfie dikategorikan ke dalam kategori yang ditetapkan. Sangat menarik untuk mengamati bahwa kategori yang paling sering dari semua foto selfie adalah alamsebanyak $46 \%$ dan secara signifikan mendominasi semua kategori lainnya. Jadi, karena tempat-tempat selfie merupakanecotourismadalah untuk menyimpulkan bahwa travel selfie, dalam kasus kategorisasi secara keseluruhan, mewakili destination image dan berkontribusi pada pembentukannya.

Kategori pengunjung, yang mewakili image yang hanya menunjukkan wajah manusiatidak ada konten lainnya yang nyata, telah menjadi tipe travel selfie paling populer kedua yang dibagikan di jejaring sosial dan mewakili 32\%. Oleh karena itu, travel selfie memenuhi fungsi presentasi diri yang sama dengan foto selfie klasik. Selain itu, kategori image sebanyak 14\% dan lokasi sebanyak 8\% mewakili hampir persentase yang sama dari semua foto dan oleh karena itu mereka dapat dianggap sebagai jenis selfies branding pada suatu destinasi.

\section{Gambar 1. Grafik Kategori}

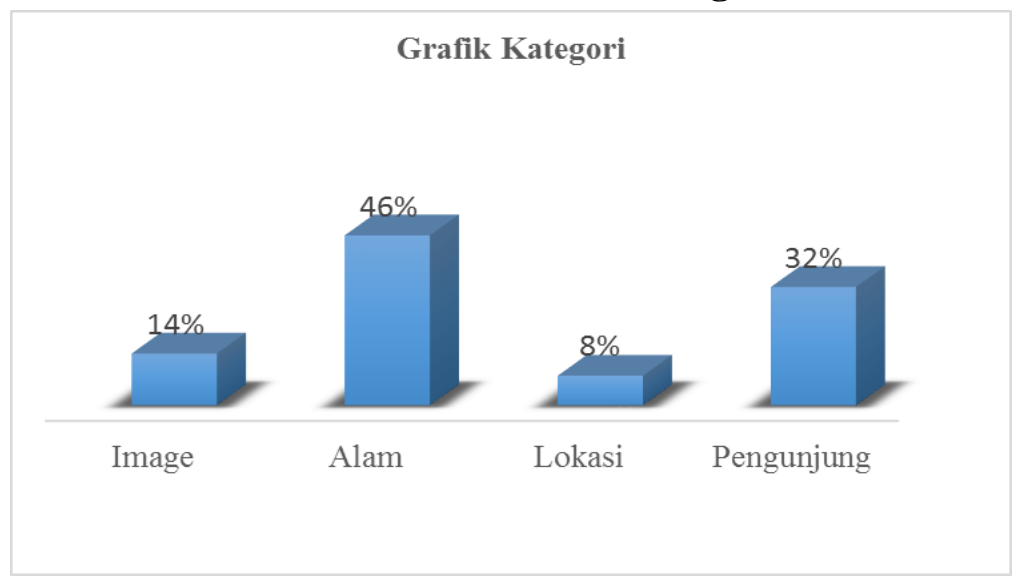

Sumber: Peneliti (2018)

Tabel 4. Daftar Semua Kategori Selfie

\begin{tabular}{lclc}
\hline Kategori & Total & Sub Kategori & Total \\
\hline \multirow{3}{*}{ Image } & \multirow{2}{*}{14} & Kebun Bunga & 2 \\
\cline { 3 - 4 } & & Taman Bunga & 2 \\
\cline { 3 - 4 } & 46 & Kebun Bunga Bantul & 10 \\
\hline Alam & \multirow{3}{*}{ Lokasi } & Bantul & 46 \\
\cline { 3 - 4 } & 8 & Jogja & 5 \\
\cline { 3 - 4 } & & Jalur Lintas Selatan & 1 \\
\hline Pengunjung & 32 & & 32 \\
\hline Jumlah & 100 & Jumlah & 100 \\
\hline \multicolumn{2}{c}{ Sumber: Peneliti } & $(2018)$ &
\end{tabular}




\section{National Conference of Creative Industry: \\ Sustainable Tourism Industry for Economic Development}

Universitas Bunda Mulia, Jakarta, 5-6 September 2018 e-ISSN No: 2622-7436

Era posting selfie klasik dari diri sendiri juga telah berlalu, karena saat ini sebagian besar foto selfie diambil di tempat-tempat populer. Banyak fakta dan karakteristik yang lebih menarik dapat ditemukan mempelajari profil selfie-takers, seperti misalnya apakah orang tersebut memakai kacamata hitam atau tidak, namun ini bukan tujuan dari penelitian ini dan karena itu mungkin menjadi topik penelitian yang mungkin untuk lebih lanjut.

\section{KESIMPULAN DAN IMPLIKASI}

Penemuan pertama adalah bahwa jejaring sosial berbasis foto, facebook adalah yang paling digunakan ketika seseorang ingin mempertimbangkan jumlah foto selfie yang diposting dan dibagikan. Jejaring sosial ini pasti memberikan sebagian besar selfie, disamping itu facebook sangat populer dan banyak fitur. Setiap individu atau kelompok yang sedang melakukan traveling akan melakukan travel selfie dan dipastikan akan mengunggah selfie ke media sosial.

Penemuan kedua adalah telah terbukti bahwa foto selfie dapat menciptakan destination image, jenis konten foto yang paling sering dari masing-masing tempat wisatadiperkuat dengan data temuan. Mengacu pada data tersebut, destination image dari wisata kebun bunga kawasan jalan lingkar selatan Bantul, Yogyakarta ditekankan sebagai jenis selfie yang wisata ecotourism. Oleh karena itu, dengan penelitian di atas, telah terbukti bahwa travel selfie yang diposting secara online di berbagai jejaring sosial melakukan penciptaan bersama destination image dan mempromosikan tempat-tempat utama tempat yang sejalan dengan apa yang dipromosikan oleh manajemen destinasi resmi, meskipun selfies wisata tidak dibagikan oleh akun jaringan management destinasi.

Banyak fakta dan karakteristik yang lebih menarik dapat ditemukan dari perilaku orang melakukan selfie, seperti misalnya apakah orang tersebut memakai atribut fashion atau sesuatu yang beda, namun ini bukan tujuan dari penelitian ini dan karena itu mungkin menjadi topik penelitian yang menarik untuk diteliti lebih lanjut.

\section{DAFTAR PUSTAKA}

Andita , R. (2018, Februari 17). bisnis.tempo.co. Retrieved from tempo.co: https://bisnis.tempo.co/read/1061671/pengguna-smartphone-akan-tembus-100juta-kemenperin-siapkan-ini

Brad, R. (2010). A brief history of smartphone's. http://www.networkworld.com/slideshows/2010/061510-smartphonehistory.html\#slide1.

Chua, T. H., \& Chang, I. (2016). Foollow me and like my beautiful selfie: SIngapore teen age girls engagement in self-presentation and peer comparison on social media . Human and Behavior, 190-197.

Chung, J. Y., \& Chen, C. C. (2018). The impact of country and destination images on destination loyalty: a construal-level-theory perspective. Asia Pacific Journal of Tourism Reseacrh, 56-67. doi:https://doi.org/10.1080/10941665.2017.1399917 


\section{National Conference of Creative Industry: \\ Sustainable Tourism Industry for Economic Development}

Universitas Bunda Mulia, Jakarta, 5-6 September 2018 e-ISSN No: 2622-7436

Comprubi, R., Guia, J., \& Comas, J. (2009). La formación de la imagen turística inducida: Un modelo conceptual. PASOS.Revista De Turismo Y Patrimonio Cultural, 7(2), 255-270.

Davidson, L. (2015). Is your daily social media usage higher than average? Is your daily social media usage higher than average?, pp. http://www.telegraph.co.uk/finance/news

bysector/mediatechnologyandtelecoms/11 610959/Is-your-daily-social-mediausagehigher-than-average.html.

Dinhopl, A., \& Gretzel, U. (2016). Selfie-taking as touristic looking. Anals of Tourism Research, 126-139. doi:10.1016/j.annals.2015.12.015

Facebook. (2016). Stats. www.newsroom.fb.com/company-info.

Frochot, I., \& Batat, W. (2013). Marketing and Designing the Tourist Experience. London: Goodfellow Publishers.

Glaser, B., \& Strauss, A. (1967). The discovery of grounded theory. International Journal of Qualitative Methods. http://www.ualberta.ca/ iiqm/backissues/5_1/pdf/mills.pdf. .

Harisa, S. A. (2017, Februari). Perilaku berfoto selfie sebagai kecenderungan munculnya gaya hidup modern. Jurna Online Mahasiswa (JOM), 4(1). Retrieved Juli 30, 2018, from https://media.neliti.com/media/publications/130481-ID-perilaku-berfoto-selfiesebagai-kecender.pdf

Katadata. (2017, Agustus 29). Pengguna Ponsel Indonesia Mencapai 142\% dari Populasi. Retrieved from databoks.katadata.co.id: https://databoks.katadata.co.id/datapublish/2017/08/29/pengguna-ponselindonesia-mencapai-142-dari-populasi

Kim, H., \& Stepchenkova, S. (2015). Effect of tourist photographs on attitudes towards destination: Manifest and latent content. Tourism Management, 29-41.

Krippendorff, K. (1980). Content Analysis: An introduction to its methodology. London: Sage.

Lee , T. P., \& Kosasih, W. (2017). Exploring the Distance, Location, and Style of "Selfies". New Contributions in Information Systems and Technologies, 875884.

Lobinger, K., \& Brantner, C. (2015). In the eye of the beholder: subjective views on the authenticity of selfies. Int. J. Commun 9, 1848-1860.

Lyu, S. O. (2016). Travel selfies on social media as objectified self-presentation. Tourism Management, 185-195. doi:10.1016/j.tourman.2015.11.001

Molinillo, S., Cabanillas, F. L., \& Sanchez, R. A. (2017). Destination image on the DMO'S platfrom: official website and social media. Tourism \& Management Studies, 5-14. doi:10.18089/tms.2017.13

Munar, A. M. (2012). Social media strategies and destination management. Scandinavian Journal of Hospitaity and Tourism, 101-120.

Nasrullah, R. (2015). Media Sosial; Perspektif Komunikasi, Budaya, dan Sosioteknologi. Bandung: Simbiosa Rekatama Media.

Patel, D., \& Jermacane, D. (2015, Maret 12). Social media in travel medicine: a review. Travel Med Infect Dis, 135-42. doi:10.1016/j.tmaid.2015.03.006

Pew Research Center. (13 Februari 2014). Emerging nations embrace internet, mobile technology. Washington: Pew Research Center. 
Qiu, L., Lu, J., Yang, S., Qu, W., \& Zhu, T. (2015, November). What does your selfie say about you? . Computers in Human Behavior, 443-449. doi:https://doi.org/10.1016/j.chb.2015.06.032

Rabassa, F. N., Paniagua, F. J., \& Setó, P. D. (2014). Estudio de la visibilidad de los posts en Facebook de diferentes destinos turísticos españoles y su co-mediación según el contenido. Congreso Turismo y Tecnologías de la Información y las Comunicaciones, 3-4.

Rasmi, S., Ng, S., Lee, J. A., \& Soutar, G. N. (2014). Tourists strategies: An acculturation approach. Tourism Management, 311-320.

Ryan, T., Allen, K. A., Gray, D. L., \& McInerney, D. M. (2017). How Social Are Social Media? A Review of Online Social Behaviour and Connectedness. Journal of Relationships Research, 1-8. doi:10.1017/jrr.2017.13

Sorokowski, P., Sorokowska, A., Oleszkiewicz, A., Frackowiak, T., Huk, A., \& Pisanski, K. (2015). Selfie posting behaviors are associated with narcissism among men. Personal. Individ. Differ, 123-127. doi:10.1016/j.paid.2015.05.004

Stelzne, M. A. (2016). Social Media marketing Industry Report: How Marketers Are Using Social Media to Grow Their Businesses. http://www.socialmediaexaminer.com/soc ial-media-marketing-industryreport2016/.

Weber, R. P. (1985). Basic content analysis. New Delhi: Sage.

Williamson , P., Stohlman , T., \& Polinsky , H. (2017). Me, My "Selfie" and I: A Survey of Self-disclosure Motivations on Social Media. IAFOR Journal of Cultural Studies, 2(2), 71-85.

\section{BIODATA}

Ari Yuniarso, SE., M.Par. merupakan Faculty Member di Program Studi DIV Perhotelan Bina Nusantara University, Jakarta

Tri Wiyana, SE., M.Par. merupakan Faculty Member di Program Studi DIV Perhotelan Bina Nusantara University, Jakarta

Dr. Arif Zulkarnain, SE., MM. merupakan Faculty Member di Program Studi DIV Perhotelan Bina Nusantara University, Jakarta

Iwan Khrisnanto, SS., M.Hum. merupakan Faculty Member di Program Studi DIV Perhotelan Bina Nusantara University, Jakarta 